These are checklists used in the neonatal resuscitation workshop. They include instructions about the simulation, the prompt given to groups before the simulation began, steps that should have been completed, and prompts to be given by the instructor during the resuscitation. The scenarios include cord prolapse, meconium aspiration, prematurity and placental abruption, and were adapted from the $6^{\text {th }}$ Edition of NRP to conform to the available resuscitation equipment, resources and practices at Hospital Enrique Aguilar Cerrato in Honduras where the workshop was held. 


\section{Cord Prolapse}

Instructions: I will read the scenario out loud. Please indicate with your actions and say out loud what you will do to take care of this infant. I will not provide any feedback until the end of the scenario.

Prompt: "You are called to the delivery of a full-term infant whose mother just arrived at the hospital and was found to have a cord prolapse. The obstetricians are preparing for an emergency caesarean section. Please demonstrate how you will prepare for the birth."

\begin{tabular}{|c|c|c|c|}
\hline & Done & Not Done & Comments \\
\hline \multicolumn{4}{|l|}{$\begin{array}{l}\text { Prepares and checks necessary equipment } \\
\text { Prompt: "The infant is delivered. The infant is not crying and is limp." }\end{array}$} \\
\hline \multicolumn{4}{|l|}{ Dries infant with towel or blanket, stimulates infant by rubbing back } \\
\hline \multicolumn{4}{|l|}{$\begin{array}{l}\text { Assesses breathing and heart rate } \\
\text { Prompt: "The infant is not breathing. The heart rate is }<100 . "\end{array}$} \\
\hline \multicolumn{4}{|l|}{ Recognizes need for bag/mask ventilation } \\
\hline \multicolumn{4}{|l|}{ Begins bag/mask ventilation at $40-60$ breaths/minute } \\
\hline \multicolumn{4}{|l|}{$\begin{array}{l}\text { Assesses breathing and heart rate } \\
\text { Prompt: "The infant is not breathing and there is no chest rise. The HR is } 80 . "\end{array}$} \\
\hline \multicolumn{4}{|l|}{$\begin{array}{l}\text { Takes ventilation corrective steps (adjust mask, repositions airway, suctions, } \\
\text { opens mouth, increases pressure, consider alternative airway) }\end{array}$} \\
\hline \multicolumn{4}{|l|}{$\begin{array}{l}\text { Assesses breathing and heart rate } \\
\text { Prompt: "The infant is still not breathing. The heart rate is }<60 . "\end{array}$} \\
\hline \multicolumn{4}{|l|}{ Recognizes need for chest compressions } \\
\hline \multicolumn{4}{|l|}{ Begins chest compressions using appropriate technique } \\
\hline \multicolumn{4}{|l|}{ Coordinates compressions with PPV (3:1 cycles) } \\
\hline \multicolumn{4}{|l|}{ Recognizes need for intubation } \\
\hline \multicolumn{4}{|l|}{ Intubates with appropriately-sized endotracheal tube } \\
\hline \multicolumn{4}{|l|}{ Verifies appropriate endotracheal tube placement } \\
\hline \multicolumn{4}{|l|}{$\begin{array}{l}\text { Assesses breathing and heart rate } \\
\text { Prompt: "The infant is still not breathing. The heart rate is now <60." }\end{array}$} \\
\hline \multicolumn{4}{|l|}{ Recognizes need for epinephrine } \\
\hline \multicolumn{4}{|l|}{ EITHER: Draws up and gives appropriate dose of epinephrine via ETT } \\
\hline \multicolumn{4}{|l|}{ OR: Prepares equipment for UVC and inserts UVC } \\
\hline \multicolumn{4}{|l|}{ Draws up and gives appropriate dose of IV epinephrine via UVC } \\
\hline $\begin{array}{l}\text { Assesses breathing and heart rate } \\
\text { Prompt: "The heart rate rises to }>100 \text {. After several minutes, the infant } \\
\text { begins to make occasional respiratory effort." }\end{array}$ & & & \\
\hline
\end{tabular}




\section{Meconium Aspiration}

Equipment: Bag/mask, laryngoscope, endotracheal tube, meconium aspirator, suction, blankets

Instructions: I will read the scenario out loud. Please indicate with your actions and say out loud what you will do to take care of this infant. I will not provide any feedback until the end of the scenario.

Prompt: "You are called to the delivery of a full-term infant. Rupture of membranes occurred several hours ago and was found to be meconiumstained. The infant will be delivered soon. Please demonstrate how you will prepare for the birth."

\begin{tabular}{|c|c|c|c|}
\hline & Done & Not Done & Comments \\
\hline \multicolumn{4}{|l|}{$\begin{array}{l}\text { Prepares and checks necessary equipment } \\
\text { Prompt: "The infant is delivered. The infant is covered in } \\
\text { meconium-stained fluid. Please show how you will care for the } \\
\text { infant." }\end{array}$} \\
\hline \multicolumn{4}{|l|}{$\begin{array}{l}\text { Asks if infant is breathing, crying, and has good tone } \\
\text { Prompt: "The infant is not crying and is limp." }\end{array}$} \\
\hline \multicolumn{4}{|l|}{ Does not dry or stimulate to breathe } \\
\hline \multicolumn{4}{|l|}{ Recognizes that the infant requires intubation and suction } \\
\hline \multicolumn{4}{|l|}{ Infant intubated and fluid suctioned from trachea } \\
\hline \multicolumn{4}{|l|}{ Dries infant with towel or blanket } \\
\hline \multicolumn{4}{|l|}{ Stimulates infant by rubbing back } \\
\hline \multicolumn{4}{|l|}{$\begin{array}{l}\text { Assesses breathing and heart rate } \\
\text { Prompt: "The infant is not breathing. The heart rate is }>100 \text {." }\end{array}$} \\
\hline \multicolumn{4}{|l|}{ Suctions nose and mouth and positions airway. } \\
\hline \multicolumn{4}{|l|}{ Stimulates infant by rubbing back } \\
\hline \multicolumn{4}{|l|}{$\begin{array}{l}\text { Assesses breathing and heart rate } \\
\text { Prompt: "The infant is still not breathing. The heart rate is } \\
<100 . "\end{array}$} \\
\hline \multicolumn{4}{|l|}{ Begins bag/mask ventilation. } \\
\hline \multicolumn{4}{|l|}{ Continues ventilation at $40-60$ breaths/minute } \\
\hline $\begin{array}{l}\text { Assess breathing and heart rate } \\
\text { Prompt: "The infant begins crying. The heart rate is }>100 . "\end{array}$ & & & \\
\hline
\end{tabular}




\section{Prematurity}

Instructions: I will read the scenario out loud. Please indicate with your actions and say out loud what you will do to take care of this infant. I will not provide any feedback until the end of the scenario.

Prompt: "You are called to the delivery of a preterm infant with estimated gestational age of 29 weeks. The infant will be delivered soon. Please demonstrate how you will prepare for the birth."

\begin{tabular}{|c|c|c|c|}
\hline & Done & Not Done & Comments \\
\hline \multicolumn{4}{|l|}{$\begin{array}{l}\text { Prepares and checks necessary equipment } \\
\text { Prompt: "The infant is delivered and appears to be about } 1.2 \mathrm{~kg} \text { in size. The } \\
\text { infant is not crying and is limp. Please show how you will care for the infant." }\end{array}$} \\
\hline \multicolumn{4}{|l|}{ Places infant in bag, dries infant with towel or blanket } \\
\hline \multicolumn{4}{|l|}{ Stimulates infant by rubbing back } \\
\hline \multicolumn{4}{|l|}{$\begin{array}{l}\text { Assesses breathing } \\
\text { Prompt: "The infant has labored respiratory efforts with retractions." }\end{array}$} \\
\hline \multicolumn{4}{|l|}{ Suctions nose and mouth and positions airway. } \\
\hline \multicolumn{4}{|l|}{ Recognizes need for assisted ventilation } \\
\hline \multicolumn{4}{|l|}{ Chooses appropriately-sized mask for premature infant } \\
\hline \multicolumn{4}{|l|}{ Begins CPAP or bag/mask ventilation } \\
\hline \multicolumn{4}{|l|}{$\begin{array}{l}\text { Assesses breathing and heart rate } \\
\text { Prompt: "The infant is no longer breathing. The heart rate is <100." }\end{array}$} \\
\hline \multicolumn{4}{|l|}{ Continues bag/mask ventilation at $40-60$ breaths/minute } \\
\hline \multicolumn{4}{|l|}{$\begin{array}{l}\text { Assesses breathing and heart rate } \\
\text { Prompt: "The infant is not breathing and there is no chest rise. The HR is } 80 . "\end{array}$} \\
\hline \multicolumn{4}{|l|}{$\begin{array}{l}\text { Takes ventilation corrective steps (adjust mask, repositions airway, } \\
\text { suctions, opens mouth, increases pressure, consider alternative airway) }\end{array}$} \\
\hline \multicolumn{4}{|l|}{$\begin{array}{l}\text { Assesses breathing and heart rate } \\
\text { Prompt: "The infant is still not breathing. The heart rate is 60-100." }\end{array}$} \\
\hline \multicolumn{4}{|l|}{ Recognizes need for intubation } \\
\hline \multicolumn{4}{|l|}{ Intubates with appropriately-sized endotracheal tube } \\
\hline \multicolumn{4}{|l|}{ Verifies appropriate endotracheal tube placement } \\
\hline \multicolumn{4}{|l|}{ Begins positive-pressure ventilation at $40-60$ breaths/minute } \\
\hline \multicolumn{4}{|l|}{$\begin{array}{l}\text { Assesses breathing and heart rate } \\
\text { Prompt: "The heart rate rises to }>100 \text { and the infant becomes pinker." }\end{array}$} \\
\hline Keeps infant warm using warm blankets and hat & & & \\
\hline
\end{tabular}




\section{Abruption}

Instructions: I will read the scenario out loud. Please indicate with your actions and say out loud what you will do to take care of this infant. I will not provide any feedback until the end of the scenario.

Prompt: "You are called to the delivery of a full-term infant whose mother was found to have a severe placental abruption. The obstetricians are preparing for an emergency caesarean section. Please demonstrate how you will prepare for the birth."

\begin{tabular}{|c|c|c|c|}
\hline & Done & Not Done & Comments \\
\hline \multicolumn{4}{|l|}{$\begin{array}{l}\text { Prepares and checks necessary equipment } \\
\text { Prompt: "The infant is delivered. The infant is not crying, limp, and pale." }\end{array}$} \\
\hline \multicolumn{4}{|l|}{ Dries infant with towel or blanket, stimulates infant by rubbing back } \\
\hline \multicolumn{4}{|l|}{$\begin{array}{l}\text { Assesses breathing and heart rate } \\
\text { Prompt: "The infant is not breathing. The heart rate is }<100 . "\end{array}$} \\
\hline \multicolumn{4}{|l|}{ Recognizes need for bag/mask ventilation } \\
\hline \multicolumn{4}{|l|}{ Begins bag/mask ventilation at $40-60$ breaths/minute } \\
\hline \multicolumn{4}{|l|}{$\begin{array}{l}\text { Assesses breathing and heart rate } \\
\text { Prompt: "The infant is still not breathing. The heart rate is }<60 . "\end{array}$} \\
\hline \multicolumn{4}{|l|}{ Recognizes need for chest compressions } \\
\hline \multicolumn{4}{|l|}{ Begins chest compressions using appropriate technique } \\
\hline \multicolumn{4}{|l|}{ Coordinates compressions with PPV (3:1 cycles) } \\
\hline \multicolumn{4}{|l|}{ Recognizes need for intubation } \\
\hline \multicolumn{4}{|l|}{ Intubates and verifies appropriate endotracheal tube placement } \\
\hline \multicolumn{4}{|l|}{$\begin{array}{l}\text { Assesses breathing and heart rate } \\
\text { Prompt: "The infant is still not breathing. The heart rate is still <60." }\end{array}$} \\
\hline \multicolumn{4}{|l|}{ Recognizes need for epinephrine } \\
\hline \multicolumn{4}{|l|}{ EITHER: Draws up and gives appropriate dose of epinephrine via ETT } \\
\hline \multicolumn{4}{|l|}{ OR: Prepares equipment for UVC and inserts UVC } \\
\hline \multicolumn{4}{|l|}{ Draws up and gives appropriate dose of IV epinephrine via UVC } \\
\hline \multicolumn{4}{|l|}{$\begin{array}{l}\text { Assesses breathing and heart rate } \\
\text { Prompt: "The heart rate is } 80 . \text { The infant is pale and has poor perfusion." }\end{array}$} \\
\hline \multicolumn{4}{|l|}{ Recognizes need for volume expander (normal saline, blood) } \\
\hline \multicolumn{4}{|l|}{ Draws up correct volume and administers via UVC } \\
\hline $\begin{array}{l}\text { Assesses infant } \\
\text { Prompt: "The heart rate is 120. The infant makes occasional gasps." }\end{array}$ & & & \\
\hline
\end{tabular}

